\title{
A DECIFRAÇÃO DE UM ENIGMA: O TÍTULO "ESMERALDO DE SITU ORBIS" (1).
}

O título da célebre obra de Duarte Pacheco Pereira é composto pela palavra Esmeraldo e pela expressão De Situ Orbis. A compreensão da expressão De Situ Orbis não apresenta a mínima dificuldade. Todos os autores que abordaram o assunto foram unânimes em considerar que se trata do título da obra geográfica de Pompônio Mela, citada aliás uma trintena de vêzes por Duarte Pacheco Pereira, e que é, com a História Natural de Plínio, uma das suas duas fontes fundamentais. Outro tanto não poderemos dizer da primeira parte do título, a palavra Esmeraldo, sôbre a decifração da qual mais de meia dúzia de teses foram até agora elaboradas sem que a unanimidade se tenha feito sôbre nenhuma delas.

Começaremos pela exposição das teses apresentadas por Santos Ferreira (2), George H. T. Kimble (3), e José Dentinho (4), por nos parecer que em nada contribuem para a resolução do problema, ainda que a dêste último tenha sido a que até agora reuniu adesões mais entusiásticas (5) .

(1). - Com êste mesmo título publicámos uma versão abreviada dêste artigo, no Suplemento Semanal do Diário de Lisboa, "Vida Literária e Artística" (Lisboa, 23 de maio de 1963). Esta versão abreviada constitui ainda a primeira parte do artigo Esmeraldo de situ orbis do Dicionário de História de Portugal dirigido por Joel Serrão, Iniciativas Editoriais, Volume II, Lisboa, 1964.

(2). - Major Santos Ferreira e Antônio Ferreira Serpa: Salvador Gonsalves Zarco - (Cristóbal Colón) - Os livros de D. Tivisco, 1930, págs. 44-47. Ver também, Arthur Lobo D'Ávila e Saul Santos Ferreira: Cristóbal Colón - Salvador Gonsalves Zarco, Infante de Portugal, Lisboa, 1939, págs. $52-56$.

(3). - George H. T. Kimble, "Esmeraldo de situ orbis" by Duarte Pacheco Pereira, London, 1937, Introduction, págs. XVII-XVIII.

(4). - José Dentinho, "Esmeraldo de situ orbis" por Duarte Pacheco Pereira. Da significação de "Esmeraldo". (Diário de Lisboa, 21 de julho de 1949).

(5). - Quando da publícação da versão abreviada dêste artigo no Diário de Lisboa, o Professor José Dentinho publicou neste mesmo Diário duas notas sôbre o assunto (6-VI-63 e 27-VI-63). Não lhe respondemos então por nos parecer que as referidas notas nada alteravam ao meu artigo e às minhas conclusōes, tendo-se limitado o Professor José Dentinho a expor de nôvo e de maneira abreviada a sua tese: Contínuamos, passado um 
Santos Ferreira apresenta-nos, entre tôdas, a tese mais imprevista, pois através de conjecturas que podemos classificar de delirantes, depois de nos dizer que Cristóbal Colón não existiu (!!!) pois "Cristóbal Colón era na realidade Salvador Gonsalves Zarco" (!!!), associa êste último à redação da obra de Duarte Pacheco Pereira!!! Para Santos Ferreira, Duarte Pacheco Pereira sabia hebraico $(! ! ! \ldots)$, e teria escrito as palavras hebraicas que corresponderiam a com ou em companhia de Salvador da Madeira. As letras das palavras hebraicas corresponderiam, lidas da direita para a esquerda, as letras E M S L O D R A E, tendo com elas formado fàcilmente Duarte Pacheco Pereira a palavra ESMERALDO, nome que antepôs ao título De Situ Orbis do seu livro (6).

George H. T. Kimble dá-nos a conhecer uma sugestão que lhe teria sido feita pelo Dr. George Sheppard e que lhe teria dado a solução do enigma: existiria uma analogia filológica entre a palavra Esmeraldo e a palavra espanhola esmerado que significaria guia. E, na verdade, o Esmeraldo de situ orbis é por excelência um guia para a navegação.

Foi em vão que procurámos nos dicionários de língua espanhola a palavra esmerado com a significação que lhe dão o Dr. George Sheppard e George H. T. Kimble. No Primer Diccionario General Etimologico de la Lengua Española (7) de D. Roque Bárcia, ou no Diccionario de la Lengua Española da Real Academia Española (8), lemos: Esmerado, da. Adjectivo. Lo echo y ejecutado con esmero. Em esmero, lemos: Esmero. Masculino. Sumo cuidado $y$ atencion diligente en hacer las cosas con perfeccion. Se quisermos admitir, por absurdo, a existência de uma gralha na impressão da obra de George H. T. Kimble, e admitindo que no lugar de esmerado se deveria ler esmeraldo, ainda assim a tese de George $\mathrm{H}$. $\mathbf{T}$. Kimble não se torna mais compreensível, pois verificamos que o substantivo esmeraldo não existe na língua espanhola no masculino. Existe

ano, e já noutras paragens, pensando da mesma maneira, fato este que nunca alterou nem altera a profunda estima e admiraçāo que temos pela personalidade do Professor José Dentinho.

(6). - A tese de Santos. Ferrelra exposta e criticada por Armando Cortesäo, Cartografia e Cartógrafos Portuguêses dos séculos XV e XVI (Contribuição para um estudo completo), Volume II, Lisboa, 1935, págs. 106-107.

(7). - D. Roque Bárcia, Primer Diccionario General Etimologico de la Lengua Española, Volume II; Madrí, 1881.

(8). - Real Academia Española, Diccionario de la Lengua Espafiola, Madrí, Décima Quinta Edición, 1925. 
sim, o nome próprio Esmeraldo, ou então o substantivo feminino: Esmeralda. Femenino. Piedra preciosa transparente, formada de cuarzo verde. Em conclusão: a explicação de George $\mathrm{H}$. T. Kimble deve ser posta de lado porque se funda num sentido errôneo da palavra espanhola esmerado.

Para José Dentinho, Duarte Pacheco Pereira propôs-se estudar o mar ao longo da costa, a natureza dos fundos, as marés, etc. Ora sendo a Esmeralda uma pedra preciosa, côr ver-' de-mar, a palavra Esmeraldo é empregada em vez de marítimo, para tudo o que diz respeito ao mar. Havendo no orbis (globo terrestre) vários situs (lugares), de que situs se propõe tratar Duarte Pacheco Pereira? Se Esmeraldo fôsse um substantivo, nada esclareceria. A expressão ficaria mesmo incompleta, se Esmeraldo não qualificasse justamente situ, indicando a que situs o autor se refere. Não querendo modificar o título latino da obra, Duarte Pacheco Pereira latinizou muito simplesmente e muito corretamente a palavra portuguêsa esmeralda em Esmeraldus, não como substantivo, mas como adjetivo. Para José Dentinho trata-se de um caso normal de latinização. Esmeraldo de situ orbis (com a preposição intercalada, o que é freqüente em latim) significa muito simplesmente: acêrca do lugar verde-mar do orbe, ou acêrca do mar do globo terrestre.

$\mathrm{Na}$ nossa opinião a explicação de José Dentinho levanta uma só dificuldade, mas esta parece-nos que intransponível: a não existência da palavra Esmeraldus em latim. Com efeito, a palavra latina Smaragdus daria quando muito Smaragdo e nunca Esmeraldo (9).

(9). - Vieira de Almeida (Homens da India de Quinhentos, Lisboa, 1955, págs. 92-93), Damiāo Peres (Anotaçōes Históricas à edição do Esmeraldo de situ orbis por Duarte Pacheco Pereira da Academia Portuguêsa da História, Lisboa, 1954-1955, págs. 211-212), e Vitorino de Magalhães Godinho (Fontes Quatrocentistas para a Geografia e Economia do Saara e Guiné, na Revista de História, São Paulo, n.o 13, janeiro-março de 1953, pág. 64), referem-se à tese de José Dentinho. Vieira de Almeida limita-se a exprimir a opinião de que a tese em questão é particularmente sugestiva. Damiāo Peres expõe a tese de José Dentinho sem o menor comentário. Finalmente, Vitorino de Magalhães Godinho aceita-a sem restriçōes: o Esmeraldo de situ orbis, ou melhor, o de situ esmeraldo orbis - do lugar verde, ou marítimo do orbe, segundo a feliz interpretação que o Dr. José Dentinho dá de um enigma que resistiu longos anos aos mais penetrantes investigadores. São bem significativas desta preferência de Vitorino de Magalhães Godinho as duas referências que recentemente fêz à tese de José Dentinho: História dos Descobrimentos de Duarte Leite, Lisboa, 1959, Vol. I, pág. 490; e, A Economia dos.Descobrimentos Henriquinos, Lisboa, 1962, pág, 162 . 
Restam-nos finalmente, Pedro de Azevedo (10), Epiphanio da Silva Dias (11), Luciano Pereira da Silva (12), e Lindolfo Gomes (13), autor de duas teses, uma das quais tem, acrescentando-lhe algo mais, o nosso favor. Façamos entretanto um breve parêntese para nos inteirarmos da tese de Lindolfo Gomes que não tem o nosso favor.

$\mathrm{Na}$ segunda parte de um artigo onde é muito menos feliz do que na primeira, Lindolfo Gomes é o único autor que exprime a opinião segundo a qual Esmeraldo seria uma expressão e não uma palavra. Segundo Lindolfo Gomes, na palavra esmeraldo, sem nenhuma transposição de caracteres, poderíamos ler a frase es (ex) -m'eraldo, isto é, eis-me heraldo (pregoeiro). Ex era a forma arcaica de eis (V. Dic. da Antiga Linguagem Portuguêsa, de Brunswick, p. 123). Ex podia-se representar por es, tendo em vista a pronúncia portuguêsa, como em ex-presidente. Quanto a Arauto e heraldo, são palavras registradas no Nôvo Dicionário de Cândido de Figueiredo. Heraldo sem h era da escrita da época. Desta maneira, Esmeraldo de situ orbis significaria: Eis-me (Pacheco) pregoeiro do que existe no mundo desconhecido.

Agostinho de Campos (14) critica a hipótese de Lindolfo Gomes afirmando que nunca em português se pronunciou esmeraldo como se escrevessemos êsmeraldo ou eismeraldo, pois a pronúncia portuguêsa é ismeraldo. A idéia de Lindolfo Gomes em ler eis-me eraldo em esmeraldo corresponderia muito

(10). - Pedro de Azevedo, O significado do "Esmeraldo de situ orbis", no Boletim da Segunda Classe da Academia das Ciências de Lisboa, Volume XIX, 1925, págs. XXI-XXVI.

(11). - Epiphanio da Silva Dias, "Esmeraldo de situ arbis" por Duarte Pacheco Pereira, no Boletim da Sociedade de Geografia de Lisboa, 1903-1904, Intradução, págs. 181-182. Esta edição do Esmeraldo foi publicada em livro, em 1905; ver sôbre êste assunto, págs. 4-5.

(12). - Luciano Pereira da Silva, o "Esmeraldo" de Duarte Pacheco - Razão dêste título, nos Anais das Bibliotecas e Arquivos, Volume I, Lisboa, 1920. Este estudo voltou a ser publicado integrado em trabalho mais geral: Duarte Pacheco Pereira - precursor de Cabral, na História da Colonização Portuguêsa do Brasil, Volume I, Pôrto, 1921. Ambos foram ainda publicados nas obras Completas de Luciano Pereira da Silva, Volume II, Lisboa, 1945.

(13). - Lindolfo Gomes: o "Esmeraldo" de Duarte Pacheco, no Jornal do Brasil, Rio de Janeiro, 28 de setembro de 1937, ou nas Publicações do Congresso do Mundo Português, Volume XI, Tomo III, 2a. secção, 2a. parte, Lisboa, 1940, págs. 357-360. Após a prímelra publicação no Jornal do Brasil, Agostinho de Campos expos e comentou as teses de Lindolfo Gomes no seu Glossário (de incertezas, novidades, curiosidades da língua portuguêsa, e também de atrocidades da nossa escrita atual), Lisboa, 1938, págs. 120-122.

(14). - Ver o Glossário de Agostinho de Campos citado na nota anterior. 
mais justamente à pronúncia brasileira do que à pronúncia portuguêsa.

A crítica de Agostinho de Campos não nos parece tão convincente quanto à primeira vista possa parecer, pois não está de modo algum excluída a hipótese de que a pronúncia brasileira atual não seja a do português do século XVI, e assim êsmeraldo ou eismeraldo poderia muito bem ter sido a fonética do português de Portugal nos tempos de Duarte Pacheco Pereira. A razão porque não aceitamos esta hipótese de Lindolfo Gomes está apenas no fato de a considerarmos demasiado engenhosa, demasiado complicada, sobretudo se tivermos em conta a explicação simples, direta, a que chegaremos nas próximas linhas, ainda com o precioso auxílio do mesmo Lindolfo Gomes (15).

Vejamos agora as teses de Luciano Pereira da Silva, Pedro de Azevedo, e Epiphanio da Silva Dias; e finalmente a de Lindolfo Gomes e o algo mais que a esta falta.

Para Luciano Pereira da Silva a palavra Esmeraldo é um anagrama formado pelas letras de dois nomes: o do rei, Manuel, a quem a obra é dedicada, e o do autor do livro, Duarte. Para satisfazer às necessidades do anagrama, Luciano Pereira da Silva lembra-nos que existiam na língua portuguêsa duas outras formas para Duarte: Duardos e Eduardo, e ainda a forma latinizada, Eduardus. Por sua vez, Manuel tomaria a forma Emmanuel. E nada mais havia a fazer do que formar o anagrama Esmeraldus com as letras de Emmanuel e de Eduardus. Sendo a obra escrita em português nada mais natural que Duarte Pacheco Pereira escrevesse Esmeraldo, em vez de Esmeraldus, como se escreveria Eduardo em vez de Eduardus. Assim, Esmeraldo de situ orbis significaria, segundo Luciano Pereira da Silva, o nôvo tratado De Situ Orbis do orbe desconhecido dos geógrafos antigos - escrito pelo português Duarte e dedicado a Manuel, o rei de Portugal.

A tese de Luciano Pereira da Silva é indefensável, pois as letras que compõem os dois nomes, o do rei e o do autor da obra, são demasiado numerosas para formar a palavra do título: sobram nada menos que sete letras. No entanto, parece-nos admirável a intuição de Luciano Pereira da Silva

(15). - Ferdinand Denis, (Missal Pontifical de Esteram Gonçalves Netto, pág. 51) chamou à obra de Duarte Pacheco Pereira, Esmeraldo do mar, de situ orbis. Armando Cortesão, (Cartografia e Cartógrafos Portuguêses dos Séculos XV e XVI - Contribuição para um estuđo completo - Volume II, Lisboa, 1935, págs. 106-107) comenta desfavoràvelmente esta liberdade de Ferdinand Denis. 
quando afirma que o nome do autor do Esmeraldo de situr orbis se incluia no título. Veremos até que ponto assim é ao expormos a tese de Lindolfo Gomes e o algo mais que a esta. falta (16).

Segundo Pedro de Azevedo, Esmeraldo era um nome italiano que se teria divulgado na ilha da Madeira no século XVI. Lembra-nos Pedro de Azevedo Santo Esmeraldo martirizado em. 303, e Smaragdo ou Smaraldo, exarca da Itália em 585 e 602. Também entre os manuscritos visigóticos recolhidos pelo Padre Garcia Villada na Paleografia Española se podem ver três manuscritos relativos a comentários sôbre a regra de São Benedito cujo autor é um Smaragdus. Por outro lado - sempre segundo Pedro de Azevedo - sabemos que o dito Smaragdus de Ardón, morto em 830, escreveu uma explicatio in evangelia et epistolas, uma via regia para um príncipe da casa de França, e um comentário sôbre a ars Donati. A especialidade de Smaragdus consistia pois nas explicações e comentários. Daí a razão do título do Esmeraldo, segundo Pedro de Azevedo: o livro. de Duarte Pacheco Pereira seria um comentário e uma explicação do Mundo, não no sentido que lhe dá Pompônio Mela, mas no sentido do Orbe tal como o conheciam os portuguêses. do início do século XVI.

Pedro de Azevedo tem para nós o mérito - veremos porquê um pouco mais adiante - de se ter lembrado do célebre Esmeraldo da ilha da Madeira que êle diz ser um nome italiano, genovês na origem segundo Gaspar Fructuoso nas Saudades da Terra (17). Em tôdas as demais conjecturas e na própria con-

(16). - Pode ver-se a exposição, e nalguns casos a crítica, da tese de Luciano. Pereira da Silva, nas seguintes obras: Robert Ricard, La Côte Atlantique du Maroe au débuti du XVIe. siècle d'aprés les instructions nautiques. portugaises, in Hespéris, Paris, 1927, 2e. Trimestre, pág. 227; Armando Cortesão, Cartografia e Cartógrafos Portuguêses dos séculos XV e XVI (Contribuição para um estudo completo), Volume II, Lisboa, 1935, págs. 106-107; George H. T. Kimble, "Esmeralda de situ orbis" by Duarte Pacheco Pereira, Londres, 1937, págs. XVI $\leftarrow$ XVIII; Vieira de Almeida, Decadência do Império Português no Oriente, na História đa Expansāo Portuguêsa no Mundo, Lisboa, 1939, Volume II, págs. 299-300; Vieira de AImeida, Homens da India de Quinhentos, Lisboa, 1955, págs. 89-93; José Dentinho, "Esmeraldo de situ orbis" por Duarte Pacheco Pereira. Da significaçāo de Esmeralđo, no Diário de Lisboa de 21 de julho de 1949; Damião Peres, Anotações Históricas à edição do Esmeraldo de situ orbis por Duarte Pacheco Pereira da Academia Portuguêsa da História, Lisria, 1954-1955, págs. 209-212.

(17). - As Saudades da Terra pelo Doutor Gaspar Fructuoso (História das inas đo Pôrto Sancto, Madeira, Desertas e Selvagens), Manuscripto do Século XVI annotado por Alvaro Rodrigues de Azevedo, Funchal, 1873; ver referências a João Esmeraldo nas págs. 85, 95, 171, 173, 197 e 255. O autor desta edição, Alvaro Rodrigues de Azevedo, em nota da pág. 521, afirma 
clusão, a sua tese parece-nos que em nada contribui para a solução do enigma (18).

Para Epiphanio da Silva Dias, cuja tese é apresentada a título de hipótese, a explicação poderia estar no título do tratado de geografia e de história natural de um escritor árabe da primeira metade do século XIV, Ibn-al-Wardi, obra muito conhecida no seu tempo, e que se intitulava Pedra preciosa das maravilhas e Pérola das coisas memoráveis. Epiphanio da Silva Dias não considera como coisa impossível que Duarte Pacheco Pereira tenha dado à sua obra geográfica o nome de uma pedra preciosa, a esmeralda, empregando a palavra, não com a terminação portuguêsa ou castelhana, mas com a terminação italiana smeraldo.

Não aceitamos como suficiente a explicação avançada, em têrmos de hipótese, por Epiphanio da Silva Dias (19), mas consideramos, com Lindolfo Gomes que ela talvez contenha uma parcela da verdade. Duarte Pacheco Pereira, como Ibnal-Wardi e muitos outros, teria sido seduzido pela idéia de ligar o título da sua obra a uma pedra preciosa, que para o seu caso foi a esmeralda. E por que a esmeralda? Lindolfo

que João ou Joanim Esmeraldo não era genovês, como diz Gaspar Fructuoso, mas sim flamengo, tendo chegado à Iha da Madeira em 1480. Na Grande Enciclopédia Portuguêsa e Brasileira (Lisboa-Rio de Janeiro), lemos: "Esmeraldo" Geneal. Provém esta família de França, da província do Artois. No reinado de D. Manuel I passou a Portugal João Esmeraldo, que foi fidalgo da sua casa e morou na Ilha da Madeira. Em 1508 se lhe passou, em Malines, carta de brasão de armas, que apresentou em Portugal, as quais lhe foram confirmadas por carta datada de Evora, 16-V-1520. Provou, para tal fim, descender dos Esmeraldos, dos de Levargua, da casa de Fimes e dos senhores de Norduchel, linhagens antigas e nobres da Picardia, Flandres e Brabante. Êste João Esmeraldo, chamado o Velho, para se distinguir de um filho de nome igual, casou-se com Águeda de Abreu, instituindo ambos, em 1522, o morgado dos Esmeraldos, no Funchal, que êle acrescentou em 1527. A sua descendência conservou-se nas ilhas, vivendo distintamente...". Ainda nesta mesma Enciclopédia, lemos: "Esmeraldo (João). Nobre francês qué vivia na Ilha da Madeira no século $\mathrm{XV}$, ali tendo adquirido fartos terrenos a Rui Gonçalves da Cunha. Recebeu Cristóvão Colombo, quando êste foi à Madeira".

(18). - A tese de Pedro de Azevedo é exposta sem comentários por Damiāo Peres nas Anotaçóes Históricas à edição do Esmeraldo de situ orbis da Acađemia Portuguêsa da História, Lisboa, 1954-1955, págs 210-211.

(19). - Pode ver-se a exposição e a crítica da tese de Epiphanio da Silva Dias, nas seguintes obras: Vieira de Almeida, Decadência do Império Português no Oriente, na História da Expansão Portuguêsa no Mundo, Lišboa, 1939, Volume II, págs. 299-300; Vieira de Almeida, Homens da fndia de Quinhentos, Lisboa, 1955, págs. 89-93; George H. T. Kimble, "Esmeraldo de situ orbis" by Duarte Pacheco Pereira, London, 1937, págs. XVII-XVIII; José Dentinho, "Esmeraldo de situ orbis", por Duarte Pacheco Pereira. Da significação de Esmeraldo, no Diário de Lisboa de 21 de julho de 1949 . 
Gomes esclarece-nos quando diz que a esmeralda (em italiano smeraldo) na fndia diz-se pachec, como se pode ver nos Colóquios dos Simples e Drogas da India de Garcia de Orta: "Esmeralda em pérsio e em língua desta terra (India) se chama pachec..." (20) . Assim, segundo Lindolfo Gomes, "tendo viajado pela fndia, Duarte Pacheco não poderia desconhecer que a esmeralda naquela região se denominava pachec" (21). Duarte Pacheco Pereira teria preferido a forma italiana por causa da terminação em o, letra pela qual acabam em geral, na língua portuguêsa, todos os nomes masculinos, e em particular o seu próprio nome, Pacheco.

Esta explicação de Lindolfo Gomes impõe-se, quanto a nós, pela sua simplicidade (22). Mas algo lhe falta. Em nossa opinião falta explicar de maneira válida a preferência de Duarte Pacheco Pereira pela forma italiana. Já Epiphanio da Silva Dias, depois Pedro de Azevedo, e agora Lindolfo Gomes, tropeçaram com a forma italiana smeraldo. Consideramos mesmo significativo o fato de vários autores terem esbarrado com a mesma dificuldade. Por que se teria lembrado Duarte Pacheco Pereira da forma italiana? Talvez estejamos em situação de o explicar se acrescentarmos a tudo o que foi dito, o seguinte: 1) sabemos que as fontes mais importantes da obra de Duarte Pacheco Pereira são o De Situ Orbis de Pompônio Mela e a História Natural de Plínio; 2) sabemos que o último livro da História Natural de Plínio, o Livro XXXVII, tem vários capítulos dedicados às esmeraldas, pedras preciosas; 3 ) sabemos que Duarte Pacheco Pereira leu, e utilizou na redação da sua obra, a História Natural de Plínio na tradução italiana de Christophoro Landino, publicada em Veneza em 1476

(20). - Garcia de Orta, Colóquios dos Simples e Drogas da India, edição publicada pela Academia das Ciências de Lisboa, dirigida e anotada pelo Conde de Ficalho, Lisboa, 1891, pág. 220. Lindolfo Gomes cita êste texto dos Colóquios pela edição de Varnhagen; f. $167 \mathrm{v}$.

(21). - Na verdade, Duarte Pacheco Pereira, acompanha Afonso de Albuquerque e Francisco de Albuquerque à f́ndia em 1503, onde permanece dois anos, regressando a Portugal em 20 de junho ou 20 de julho de 1505. E' logo à chegada da India, muito provàvelmente em agôsto, que Duarte Pacheco Pereira começa a redação da sua obra.

(22). - $\mathrm{O}_{\mathrm{s}}$ únicos autores que se referem a esta tese de Lindolfo Gomes são Agosîinho de Campos (Glossário - de incertezas, novidades, curiosidades da língua portuguêsa, e também de atrocidadés da nossa escrita atual Lisboa, 1938, págs. 119-122) e Vieira de Almeida (Decadência do Império Português no Oriente, na História da Expansão Portuguêsa no Mundo, Lisboa, 1939, Volume II, págs. 299-300, e Homens da fndia de Quinhen tos, Lisboa, 1955, págs. 89-93). Para Agostinho de Campos o erudito brasileiro teria encontrado a solução definitiva para o velho enigma. Vieira de Almeida é particularmente impressionado pela tese de Lindolfo Gomes, ainda que hesite entre esta e a de José Dentinho. 
e 1481 (23), sendo freqüentíssimos nesta tradução italiana, nos capítulos referentes às esmeraldas (Livro XXXVII, Capítulos VI e VII), os empregos da forma italiana smeraldo. Vejamos a título de exemplo, os seguintes passos: raldo".

"Nerone vedeva le battagle de gladiatori in uno sme-

"Et dicono che... a un lione di marmo furone facti gli occhi di smeraldo".

"Scrive Juba che lo smeraldo el quale chiamano Colan si lega in Arabia ne gli ornamenti degli edificii a la pietra la quale in Egypto e chiamata Alabastrite".

"Uno smeraldo lungo quattro gomiti \& largo tre".

"El Colosseo Serapi di smeraldo di nove gomiti".

"La somma del colore e composta daria \& di purpura \& mancavi el verde dello smeraldo" (24).

As duas fontes mais importantes da obra de Duarte Pacheco Pereira estão assim na origem do seu título. O Esmeraldo

(23). - Historia Naturale di C. Plinio Secondo, tradocta di lingua latina in fiorentina per Christophoro Landino Fiorentino al Serenissimo Ferdinando Re di Napoli, Venetiis, 1476; Naturale historia di G. Plinio Secondo, tradocta in lingua fiorentina per Christophoro Landino, Venetiis, 1481. Ver a demonstração de que Duarte Pacheco Pereira se serviu desta tradução italiana da obra de Plínio na redação do seu Esmeraldo de situ orbis, nos nossos trabalhos: "Esmeraldo de situ orbis" de Duarte Pacheco Pereira (Edition critique et commentée), no prelo; L"'Esmeraldo de situ orbis" de Duarte Pacheco Pereira et la littérature portugaise de voyages à l'époque des grandes découvertes, em preparação. Também já a êste assunto nos referimos, nas seguintes publicações: Um inédito de Duarte Pacheco Pereira existente na Biblioteca da Ajuda, no Diário de Lisboa de 17 e 19 de julho de 1961; Um inédito de Duarte Pacheco Pereira, no Boletim Iinternacional de Bibliografia Luso-Brasileira, Fundação Calouste Gulbenkian, Volume II, n.o 4, Lisboa, outubro-dezembro de 1961; "Esmeraldo de situ orbis" de Duarte Pacheco Pereira (Edition critique et commentée), in Positions des Thèses de Troisième Cycle soutenues devant la Faculté en 1960 et 1961, Publications de la Faculté des Lettres et Sciences Humaines de Paris, Presses Universitaires de France, Paris, 1962; Esmeraldo de situ orbis, no Dicionário de História de Portugal dirigido por Joel Serrão, Iniciativas Editoriais, Lisboa, 1963; As fontes de Duarte Pacheco Pereira no "Esmeraldo de. situ orbis" (Breve apontamento), in Publicaciones del Curso Hispano-Portugues de Orense, 1963. - Quando dizemos que o Livro XXXVII da obra de Plínio contém vários capítulos dedicados às esmeraldas, referimo-nos às edições modernas, como a de Littré (Histoire Naturelle... avec la traduction en français par $M$. $E$. Littré, 2 Volumes, Paris, 1848-1850), onde se podem ver, pelo menos, quatro capítulos sôbre o assunto: Capítulos 16, 17, 18, 19. Nas ediçōes antigas, sejam latinas, sejam as italianas de Landino, a divisâo da obra em capitulos é completamente diferente, e por isso só dois capítulos, o VI e VII do Livro XXXVII, se ocupam do assunto.

(24). - São nossos os sublinhados da palavra smeraldo. 
de situ orbis é pois o De Situ Orbis de Pacheco, o De Situ Orbis dos tempos modernos, destinado a substituir o De Situ Orbis da antigüidade, o de Pompônio Mela .

JOAQUIM BARRADAS DE CARVALHO Professor de História Ibérica da Faculdade de Filosofia, Ciências e Letras da Universidade de São Paulo. 